\title{
Osteogenesis Modulation: Induction of Mandibular Bone Growth in Adults by Electrical Field for Aesthetic Purposes
}

\author{
Gregorio Hernandez Zendejas ${ }^{1} \cdot$ Marek K. Dobke ${ }^{1}$ Andrew Phelps ${ }^{1} \cdot$ \\ Gabriel Planas ${ }^{2} \cdot$ Marco Sanchez $^{2}$
}

\begin{abstract}
Background A new technique in plastic surgery termed Osteogenesis Modulation is described. This technique uses a surgically implanted, battery-operated medical device to deliver customized electrical pulses to produce mandibular bone growth. This device was designed to be a temporary, nonpermanent implant. The purpose of this study was to review both the safety and efficacy of Osteogenesis Modulation.

Methods This study comprises two phases. Phase I involved experimental technology development and animal experiments. Phase II included technology development for clinical use and a clinical trial. In Phase II, four patients with a diagnosis of mandibular hypoplasia and microgenia underwent surgical implantation of the novel medical device over the chin bone. Once a satisfactory change of contour of mandibular bone was achieved, the devices were removed. In all patients, the devices were left in place for 12 months, then surgically removed under local anesthesia. Preoperative and long-term postoperative cephalometric controls were done.

Results In all patients, symmetrical mandibular bone growth was observed with good-to-excellent aesthetic results. The overall follow-up period was 39 months. Cephalometric controls taken 3 to 6 months after the device removal showed an average increase in mandible length of $5.26 \mathrm{~mm}$ (range, $2.83-7.60 \mathrm{~mm}$ )
\end{abstract}

Marek K. Dobke

mdobke@health.ucsd.edu

1 University of California Medical Center, 200 West Arbor Drive, San Diego, CA 92103-8890, USA

2 Jalisco Institute for Reconstructive Plastic Surgery, 2022 Federalismo Norte, 44220 Guadalajara, Jalisco, Mexico
Conclusions Preliminary clinical results suggest that Osteogenesis Modulation is a safe, minimally invasive, and effective alternative treatment for the correction of mandibular hypoplasia in selected cases.

Level of Evidence IV This journal requires that authors assign a level of evidence to each article. For a full description of these Evidence-Based Medicine ratings, please refer to the Table of Contents or the online Instructions to Authors www.springer.com/00266.

Keywords Facial implant · Mandibular hypoplasia . Microgenia · Genioplasty · Osteogenesis · Osteotomy

\section{Introduction}

Mandibular hypoplasia and microgenia continue to be common facial skeleton deformities. The treatment of mandibular hypoplasia and microgenia involves either osteotomies, bilateral sagittal split osteotomy (BSSO), genioplasty, distraction osteogenesis, or alloplastic implants [1-7]. Osteotomies, BSSO, genioplasty, and distraction osteogenesis require general anesthesia and a long postoperative recovery. Alloplastic implants are utilized for aesthetic improvement of the facial profile. However, alloplastic implants may cause underlying bone resorption and foreign body reaction [8,9]. Resorbable tissue fillers offer a minimally invasive, but temporary solution.

Bone formation and resorption is a dynamic lifelong process. Multiple factors influence bone formation and its remodeling. Recognizing the potential of piezoelectric effect on bone described by some authors [10-24] we developed a new device and technique to produce mandibular bone growth. The purpose of this study was to achieve correction of mandibular hypoplasia and 
microgenia without using osteotomies, BSSO, genioplasty, distraction osteogenesis, alloplastic implants, or tissue fillers. This study comprises two phases. Phase I involved experimental technology development and animal experiments. Phase II included technology development for clinical use and a clinical trial.

\section{Materials and Methods}

\section{Phase I: Animal Experiments}

From June 1999 to March 2001, an experimental study was performed. The study involved four 7-week-old Wistar rats. To elucidate the biological effects of various types of electrical pulses on the mandibles of rats, we developed an experimental, miniaturized, implantable pulse generator (Fig. 1). This experimental device was designed, engineered, and assembled by the first author (G.H.Z.) assisted by a small team of engineers. This device was designed to be a temporary, nonpermanent implant. The experimental pulse generator technical specifications are as follows: The generator comprises a platinum-coated main case containing circuitry and a battery. The main case outer dimensions are $15.0 \times 13.0 \times 3.5 \mathrm{~mm}$. This case is connected to a platinum active plate through a silicone-coated lead. The electric pulses are delivered by the active plate. The dimensions of the active plate are $11.0 \times 3.0 \times 0.6 \mathrm{~mm}$. The generator may include one or two active plates. The generator can produce pulses with variable polarity mode, waveform, pulse frequency, pulse amplitude, and pulse width.

For this experimental study, we built three generator models as follows:

1. The first generator comprised one active plate delivering negative polarity pulses with the following

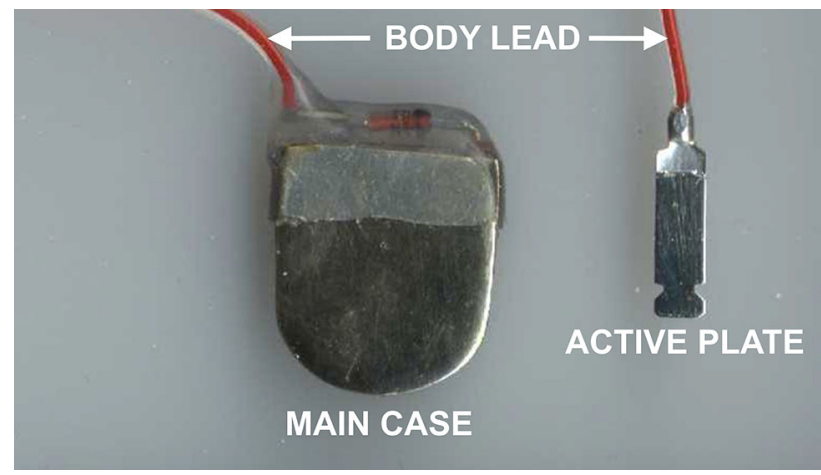

Fig. 1 The experimental pulse generator. The generator comprises a platinum-coated main case containing circuitry and a battery. This case is connected to a platinum active plate through a silicone-coated lead. The electric pulses are delivered by the active plate characteristics: Rectangular waveform, frequency $=$ $0.5 \mathrm{~Hz}$, pulse amplitude $=-720$ millivolt, pulse width $=4$ milliseconds.

2. The second generator comprised one active plate delivering negative polarity pulses with the following characteristics: Rectangular waveform, frequency = $0.5 \mathrm{~Hz}$, pulse amplitude $=-1180$ millivolt, pulse width $=4$ milliseconds.

3. The third generator comprised two active plates. The first plate of the third generator delivered negative polarity pulses with the following characteristics: Rectangular waveform, frequency $=0.5 \mathrm{~Hz}$, pulse amplitude $=-1360$ millivolt, pulse width $=4$ milliseconds. The second plate of the third generator delivered positive polarity pulses with the following characteristics: Rectangular waveform, frequency = $0.5 \mathrm{~Hz}$, pulse amplitude $=+1360$ millivolt, pulse width $=4$ milliseconds.

The implantation of the experimental pulse generator was carried out as follows (Fig. 2): Under general anesthesia, an incision was made on the rat's back. A second small incision was made on the skin over the mandible body. The device was inserted through the rat's back incision, and the active plate was passed subcutaneously to the second incision area. Then, the plate was applied over the mandibular body and secured in place using a nylon 6-0 stitch. The skin was closed using 6-0 nylon.

To elucidate the biological effects of various types of electrical pulses on the mandibles of the rats, we allocated the generators as follows:

1. First rat: No generator was implanted. A simple platinum plate was applied to the body of the leftside mandible. The right-side mandible was left intact.

2. Second rat: The first generator was implanted. An active plate delivering negative polarity pulses of low intensity ( -720 millivolt) was applied to the body of the left-side mandible. The right-side mandible was left intact.

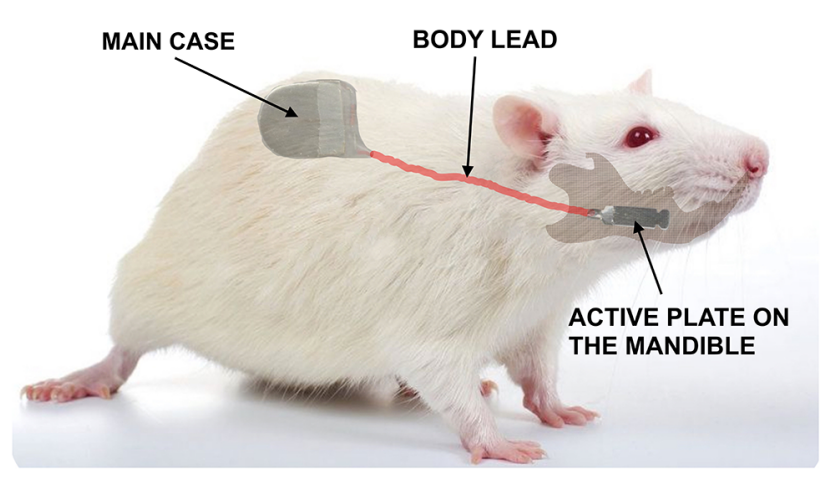

Fig. 2 Schematic representation of the subcutaneous location of the experimental pulse generator 
3. Third rat: The second generator was implanted. An active plate delivering negative polarity pulses of moderate-intensity ( -1180 millivolt) was applied to the body of the left-side mandible. The right-side mandible was left intact.

4. Fourth rat: The third generator was implanted. An active plate delivering negative polarity pulses of high intensity ( -1360 millivolt) was applied to the body of the left-side mandible. An active plate delivering positive polarity pulses of high intensity $(+1360$ millivolt) was applied to the body of the right-side mandible.

The pulse generators were left in place for four weeks, then the rats were euthanized. All mandibles were resected, cleaned from soft tissue, dried, and subjected to a threedimensional analysis.

\section{Results}

No noticeable changes occurred when a single platinum plate was applied to the mandibular body. The negative polarity pulses promoted the formation of new bone, whereas the positive polarity pulses promoted the resorption of bone. A three-dimensional analysis of the rat mandibles was carried out (Fig. 3). An increase of the mandibular thickness directly related to the intensity of the electrical pulses of negative polarity was observed. The average thickness of the control mandibles was $2.64 \mathrm{~mm}$ (range $2.60-2.66 \mathrm{~mm}$ ). The mandible thickness when lowintensity, moderate-intensity, or high-intensity negative pulses were applied was $2.70 \mathrm{~mm}, 3.43 \mathrm{~mm}$, and $3.58 \mathrm{~mm}$, respectively. The thickness of the mandible on high-intensity positive pulses was $2.15 \mathrm{~mm}$.

Changes in bone remodeling observed at the site of application of the active plate resulted in the overall measured dimensions of the mandible reflecting the fact that "local" changes may affect dentofacial measurements beyond the area of the treatment. The mean Co-Go distance of the control mandibles was $10.62 \mathrm{~mm}$ (range 10.28-10.82 $\mathrm{mm})$. The Co-Go distance when high-intensity negative pulses or high-intensity positive pulses were applied was $10.93 \mathrm{~mm}$ and $10.53 \mathrm{~mm}$, respectively. The mean Co-LIE distance of the control mandibles was $29.56 \mathrm{~mm}$ (range 29.36-29.92 mm). The Co-LIE distance when high-intensity negative pulses or high-intensity positive pulses were applied was $29.79 \mathrm{~mm}$ and $29.53 \mathrm{~mm}$, respectively. The mean Co-Me distance of the control mandibles was 23.02 $\mathrm{mm}$ (range 22.76-23.34 mm). The Co-Me distance when high-intensity negative pulses or high-intensity positive pulses were applied was $23.03 \mathrm{~mm}$ and $23.06 \mathrm{~mm}$, respectively.
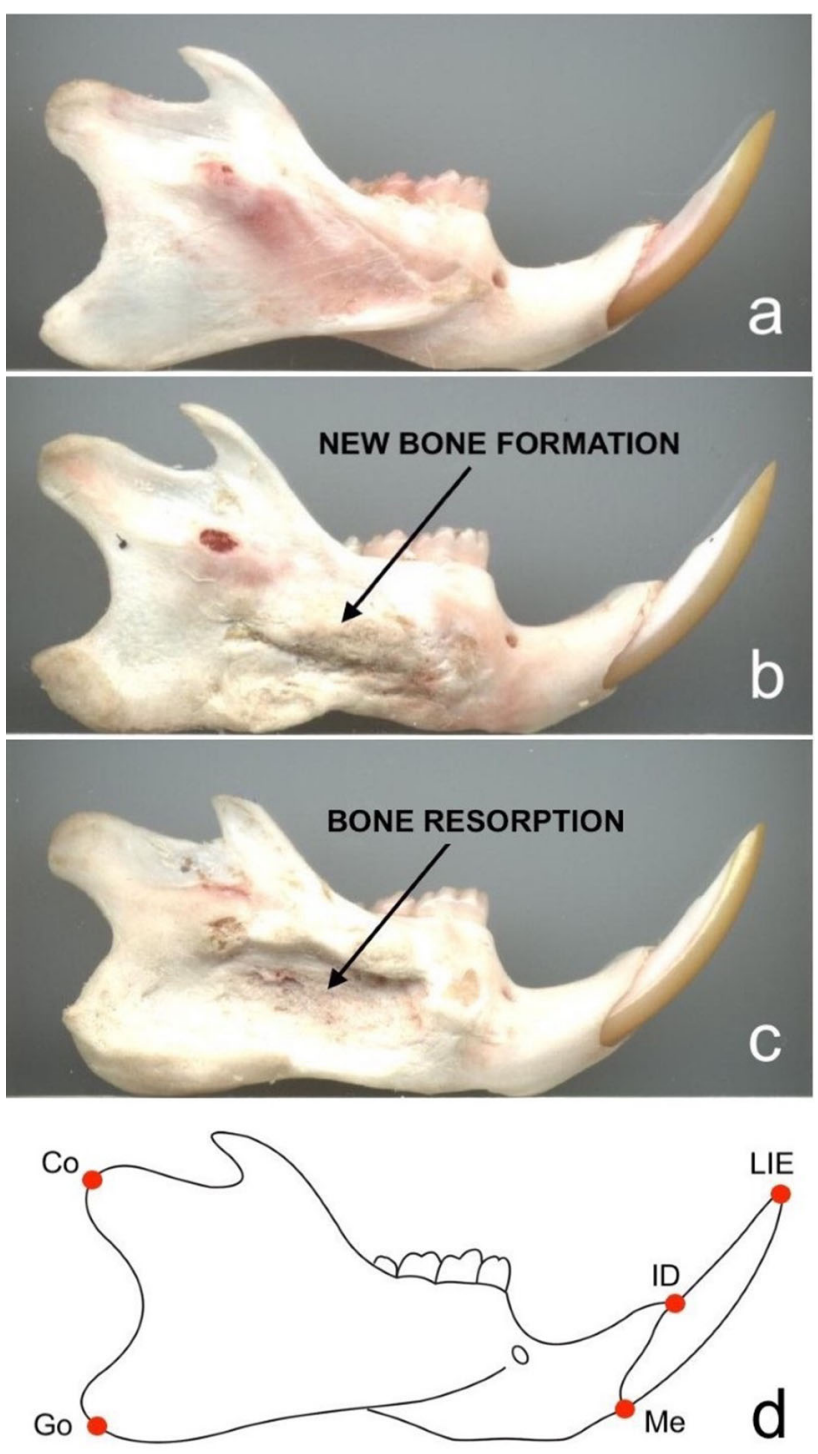

Fig. 3 Comparison of the effects of electrical pulses in the rat mandible. a Mandible where no pulses were applied. b Mandible where negative polarity pulses were applied. New bone formation is evident in the area of application of the active plate. c Mandible where positive polarity pulses were applied. Bone resorption is apparent in the area of application of the active plate. d Schematic diagram showing the skeletal landmarks used in the three-dimensional analysis of the rat mandibles. Co, condylion; Go, gonion; Me, menton; ID, infradentale; LIE, lower incisal edge. Note: the original picture (b) was flipped horizontally for didactic purposes

\section{Phase II: Clinical Experience}

From August 2003 to November 2006, a prospective, preliminary observational clinical trial was performed. Patient selection was limited to patients with mandibular hypoplasia and microgenia with normal occlusion. Four patients with a diagnosis of mandibular hypoplasia and microgenia ( 3 women and 1 man) with a mean age of 20 years (range, 15-25 years) were included. Based on the 
above-mentioned experimental study, we developed a new device and technique for clinical use. We called this new device "Osteogenesis Modulator Implant" (Modulator, for short), and the new technique "Osteogenesis Modulation" (Modulation, for short) (Fig. 4). The Modulator was designed, engineered, and assembled by the first author (G.H.Z.) assisted by a team of engineers. This device was designed to be a temporary, biocompatible, nonpermanent implant. This device is hermetically sealed and can operate continuously for 18 months. The Modulator technical specifications are as follows: The device dimensions are $30.0 \times 13.0 \times 3.0 \mathrm{~mm}$. The Modulator comprises a medical grade polymethyl methacrylate case containing miniaturized high-performance circuitry and a battery. Attached to each of its flat surfaces, are $0.1 \mathrm{~mm}$ thick medical grade gold plates, which are connected to the circuitry. One of the plates is the active plate, whereas the other is the indifferent plate. The active plate delivers negative polarity pulses with the following basic characteristics: Rectangular waveform, frequency $=4 \mathrm{~Hz}$, pulse amplitude $=-1000$ millivolt, pulse width $=1.5$ milliseconds. Some sterilized Modulator prototypes were built between July 2001 and June 2003.

The surgical technique for the implantation of the Modulator is similar to the technique for the insertion of an alloplastic chin implant. The surgical technique for the implantation of the Modulator is as follows: The midline of the chin area is marked as a reference point. The proposed
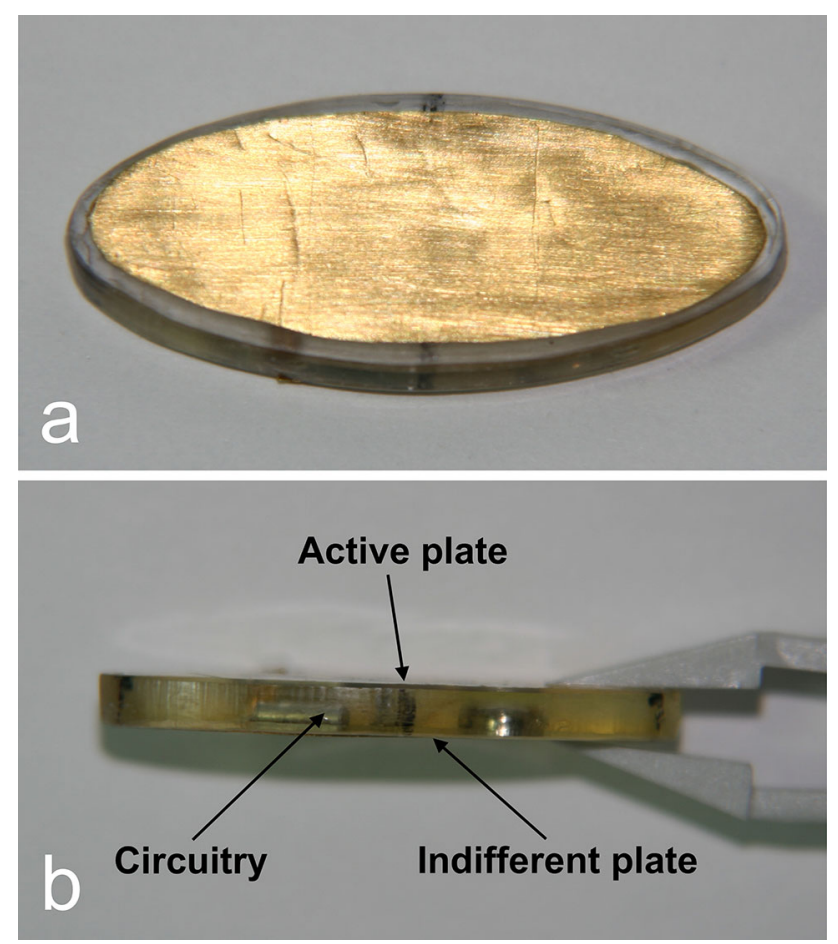

Fig. 4 The Modulator. a Top view. b Side view location of the Modulator is marked with indelible ink. Under local anesthesia with sedation, the chin is accessed through a submental incision. A subperiosteal pocket is developed to accommodate the Modulator. This pocket should be of appropriate size and shape to allow an easy and precise Modulator placement. The Modulator is inserted using special soft-touch, electrically insulated instruments to avoid device damage. During surgery, it is of uppermost importance to verify that the active plate is the one in contact with the bone. The active plate must be in contact with the chin bone to apply the electrical pulses to produce growth of the mandibular bone. During the immediate postoperative period, the patients reported a "bouncing" sensation in the chin. This sensation disappeared after few days.

Few weeks after surgery, a postoperative X-ray was taken to verify the adequate location of the Modulator. Cephalometric controls were carried out before surgery and six months after the removal of the modulator (Figs. 5, 6, 7, $8,9,10,11,12,13)$. The cephalometric analysis compared the preoperative and the long-term postoperative changes in the distances between articulare (Ar) and pogonion $(\mathrm{Pg})$ and between pogonion and infredentale (Id) cephalometric landmarks. The radiographs were also assessed for net soft tissue advancement by tracing and measuring soft tissue thickness from bony pogonion to soft tissue pogonion [25]. The postoperative follow-up included periodic monitoring of the Modulator function. This monitoring was done using an electrocardiograph (ECG), putting the ECG cutaneous electrodes over the chin area to detect the Modulator electric pulses. In all patients, the Modulators were left in place for 12 months, then surgically removed under local anesthesia.

\section{Results}

To evaluate the changes of the mandible length, we compared the preoperative and the long-term postoperative changes in the distances between $\mathrm{Ar}$ and $\mathrm{Pg}$ cephalometric landmarks. To assess chin vertical curve changes, the preoperative and postoperative distance between Id and Pg was measured. Good-to-excellent aesthetic results were achieved in all cases. The overall follow-up period was 39 months. Cephalometric controls taken 3 to 6 months after Modulator removal showed an average increase in mandible length of $5.26 \mathrm{~mm}$ (range, $2.83-7.60 \mathrm{~mm}$ ) and of vertical curve of $23.5 \mathrm{~mm}$ (range from 22 to $25 \mathrm{~mm}$ ), (Figs. 5, $6,7,8,9,10,11,12,13)$. The average increase in soft tissue projection was $90 \%$ of the thickness of "added" bone length $4.7 \mathrm{~mm}$ (range, 2.5-6.8mm). After 39 months, clinical results were maintained, with no clinical evidence of bone resorption or complications. All patients preserved a normal pretreatment occlusion. 

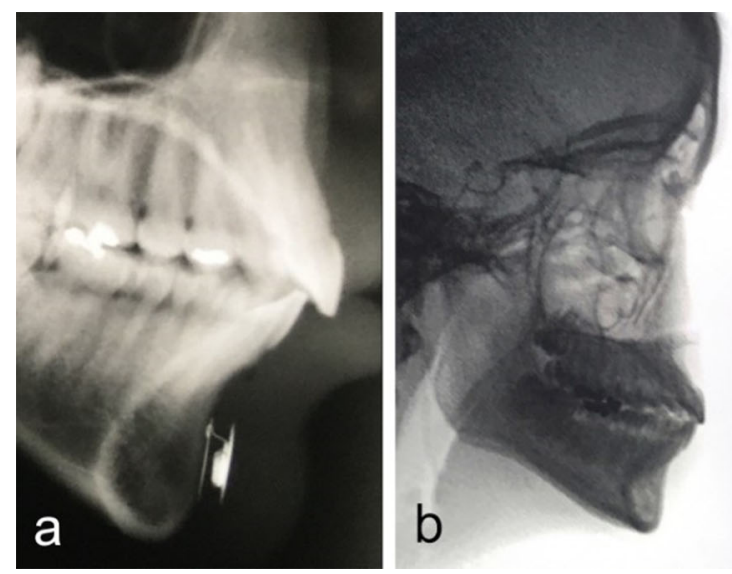

Fig. 5 a Postoperative X-ray showing the Modulator properly located over the chin bone. The active plate is in contact with the chin bone. b Example of a preoperative cephalometric radiograph. c Long-term postoperative cephalometric radiograph of the same patient, taken 6 months after the removal of the Modulator. d Comparison between preoperative (blue color) and long-term postoperative (red color) traced cephalometric radiographs of this patient, showing a $7.60 \mathrm{~mm}$

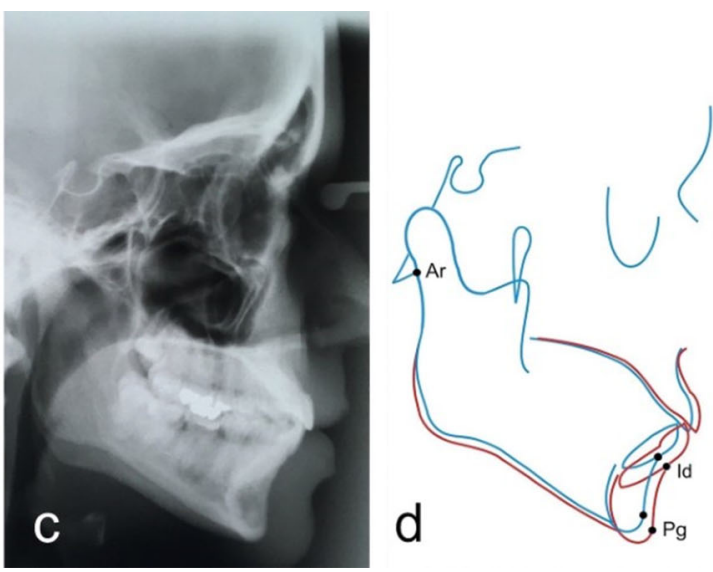

increase of mandible length and an approximately $3 \mathrm{~mm}$ increase of the length of the vertical curve between pogonion and infradentale. $\mathrm{Ar}$, articulare (junction between the inferior surface of the cranial base and the posterior border of the ascending ramus of the mandible); $\mathrm{Pg}$, pogonion (most anterior point of mandibular symphysis); Id, infradentale.
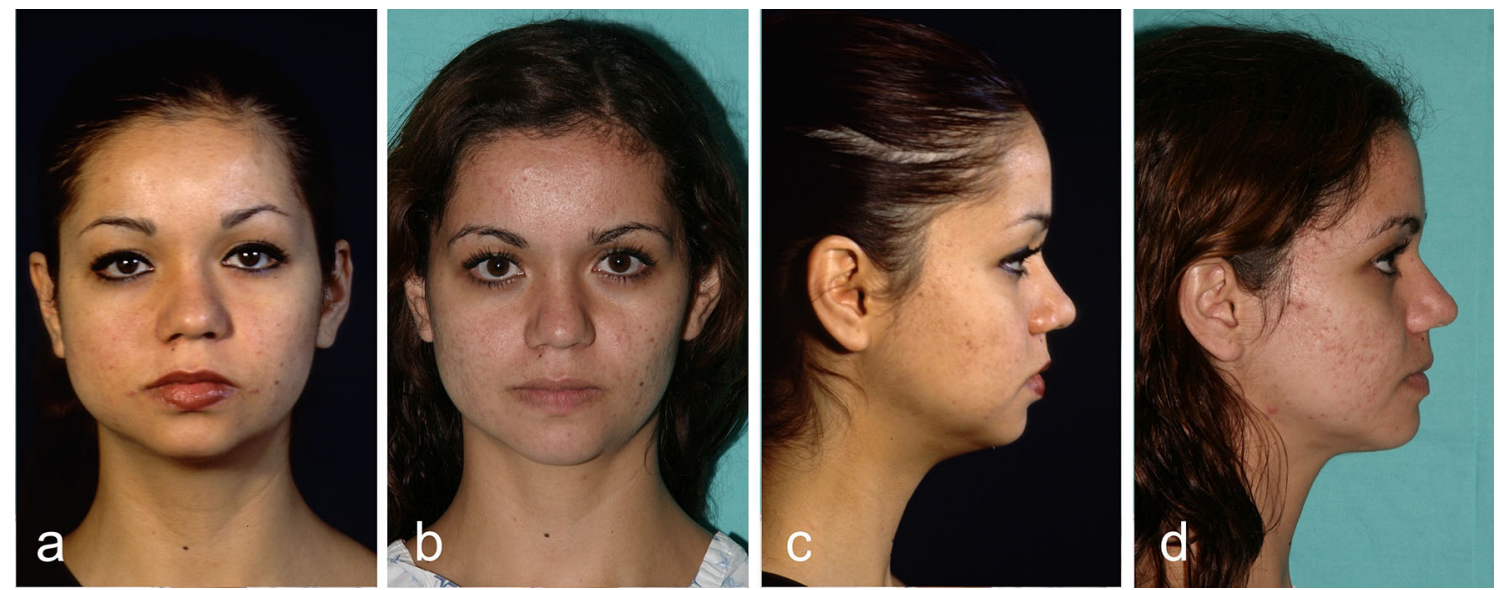

Fig. 6 This 19-year-old woman underwent Modulation, and a bichectomy procedure. a, c Preoperative view. b, d Postoperative view after 18 months.

\section{Discussion}

Principles of "tissue engineering" applied to programmable or controllable osteogenesis are attained by the Modulator. The device retains its physical properties after implantation and functions well fulfilling biological expectations [26, 27]. The piezoelectric effect is the capacity of some materials to generate an electric charge in response to applied mechanical stress. Bone exhibits the piezoelectric effect, generating electrical potentials in response to mechanical stress $[10,11]$. When the facial bones are subjected to the stress of muscular forces, electrical charges of different polarities are generated. Negative polarity charges promote bone formation, while positive polarity charges promote bone resorption [12-14].
Although there are several experimental reports about the effects of electrical stimulation on osteogenesis and bone remodeling [15-24, 28-53], the Modulator is the world's first practical, clinical facial implant capable of producing long-term, reliable and sustainable bone remodeling in intramembranous type of bone. In addition to permanent bone augmentation effect, osteogenesis was complemented by soft tissue changes. Similar, if not better outcome, comparing to results produced by implants made of hard materials, soft tissue projection was of approximately $90 \%$ of new bone thickness [25].

Modulator implantation procedure requires both a comprehensive knowledge of facial anatomy and some basic training in the use of the special instruments used to insert the Modulator. The surgical technique for the 


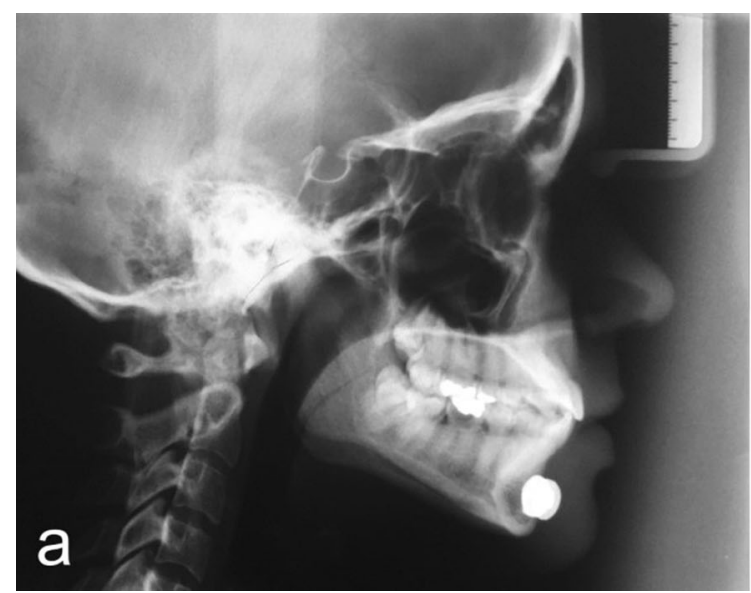

Fig. 7 The cephalometric control (a-image obtained at the beginning of the treatment and $\mathbf{b}$ - six months after the Modulator removal) showed a $7.60 \mathrm{~mm}$ overall length increase of her mandible. Full

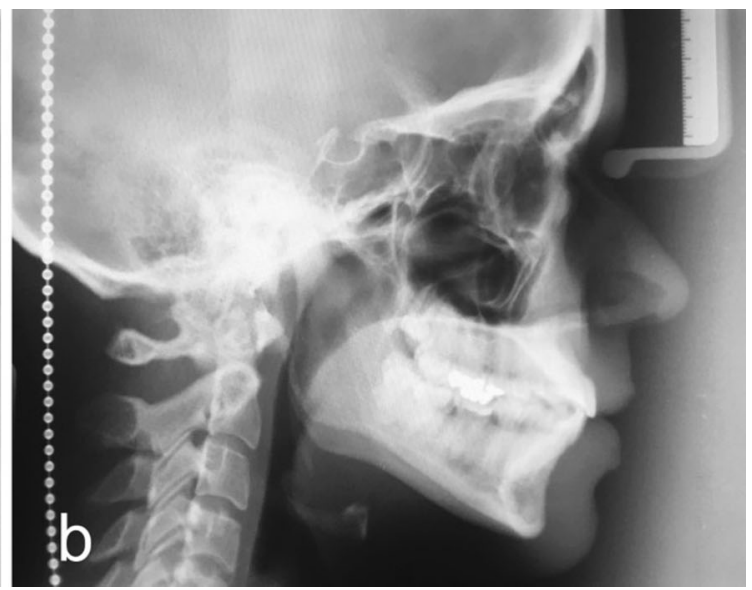

correction of the mandibular hypoplasia is evident. The change in contour is striking, not only in the body and angle of the mandible but also in the chin area.
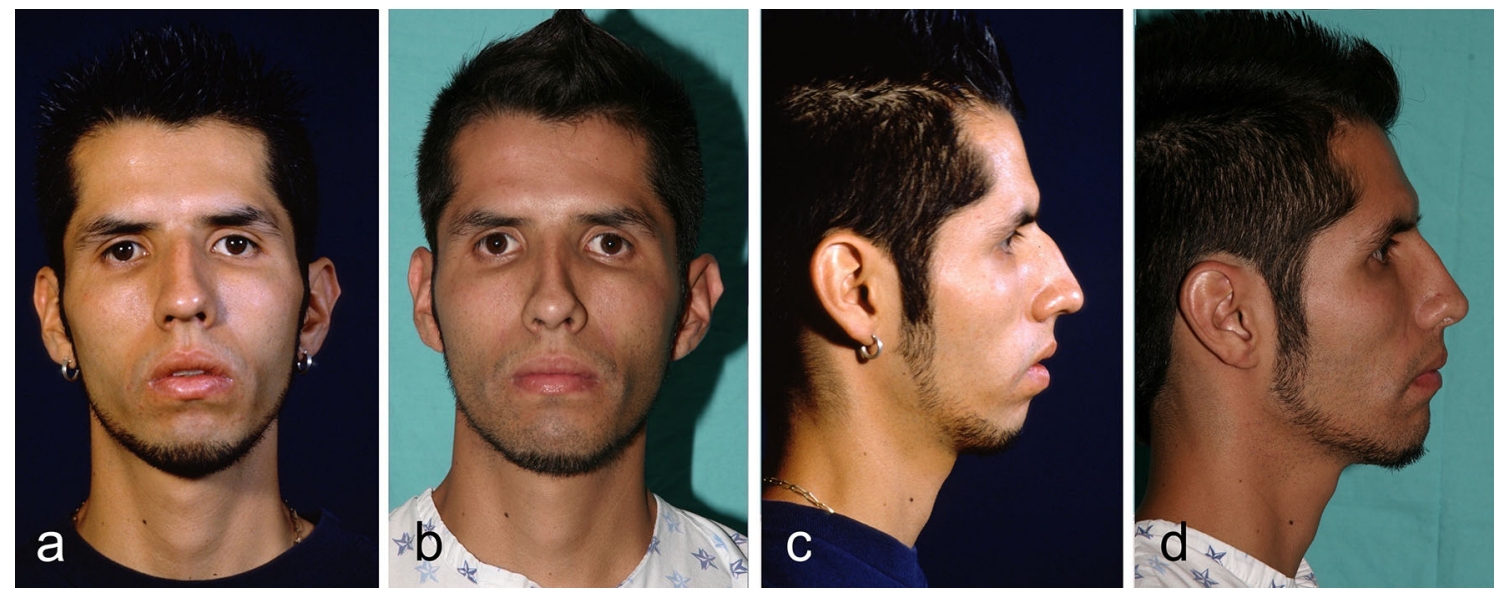

Fig. 8 Twenty-one year-old man underwent Modulation, and a rhinoplasty procedure. a, c Preoperative view. b, d Postoperative view after 18 months.

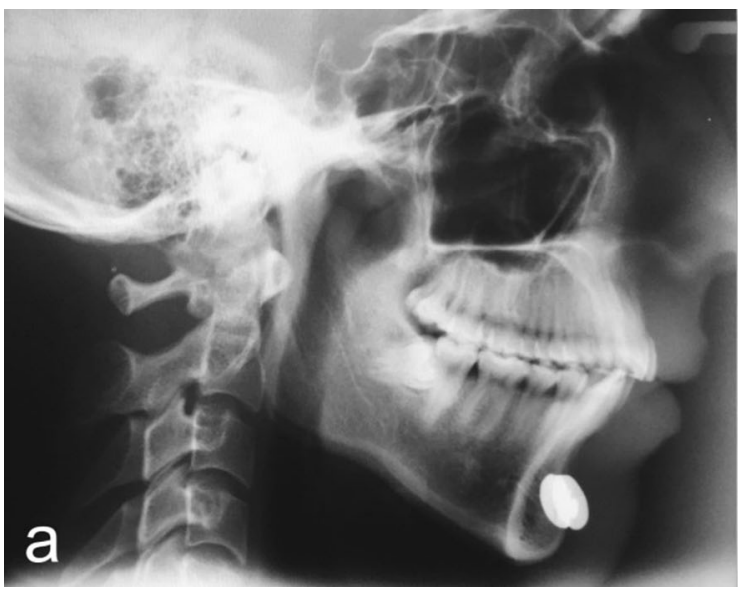

Fig. 9 The cephalometric control (a-at the beginning of the treatment and $\mathbf{b}$ - six months after the Modulator removal) showed a $4.85 \mathrm{~mm}$ overall length increase of his mandible. Correction of the

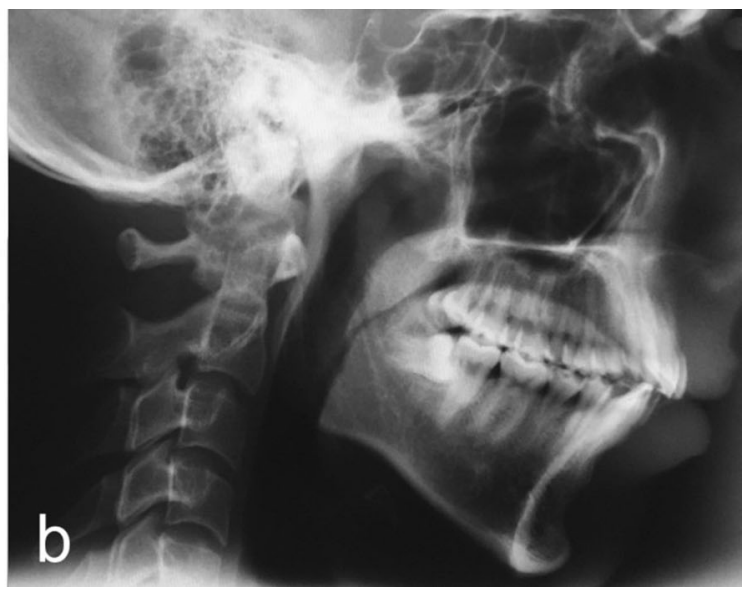

mandibular hypoplasia is apparent. The change in contour is evident, not only in the ramus and angle of the mandible, but also in the body of the mandible, and chin area. 

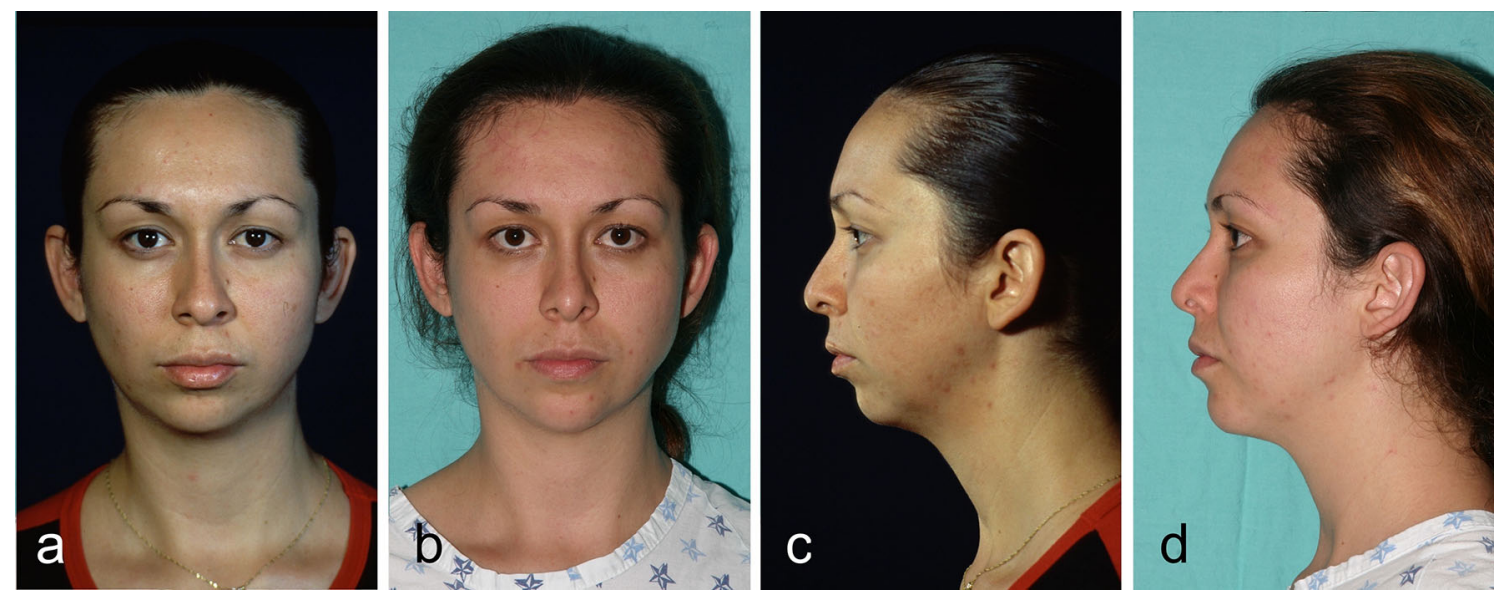

Fig. 10 Twenty-five year-old woman underwent Modulation, and a rhinoplasty procedure. a, c Preoperative view. b, d Postoperative view after 18 months.
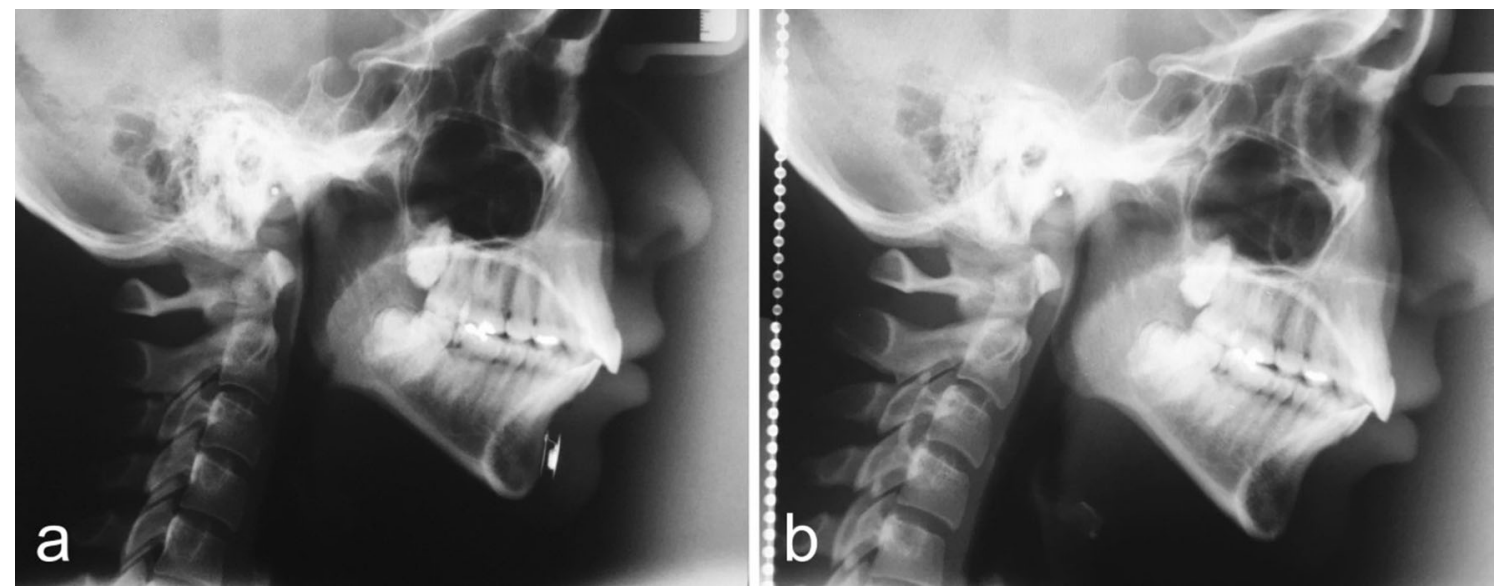

Fig 11 The cephalometric control (a-at the beginning of the treatment and $\mathbf{b}-6$ months after the Modulator removal) showed a $2.83 \mathrm{~mm}$ overall length increase of her mandible. The change in contour is noticeable, not only in the body of the mandible but also in the chin area.
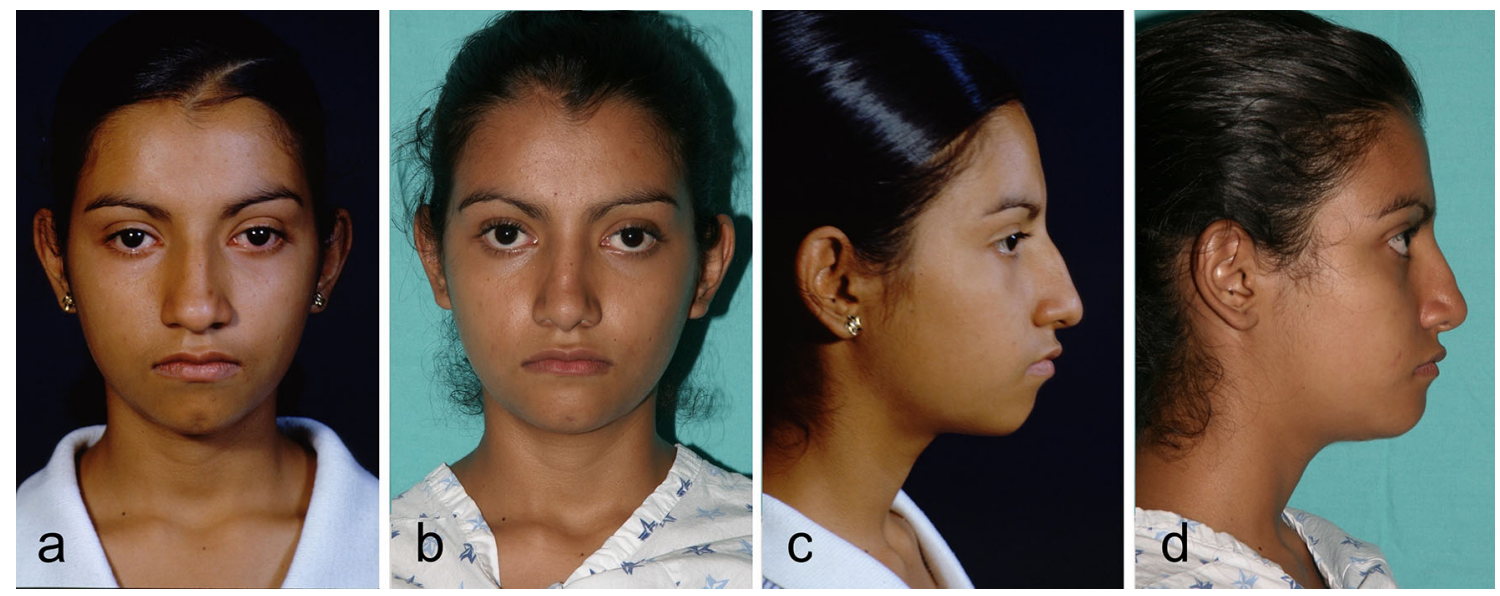

Fig. 12 Fifteen-year-old woman underwent Modulation, and a rhinoplasty procedure. a, c Preoperative view. b, d Postoperative view after 18 months. 

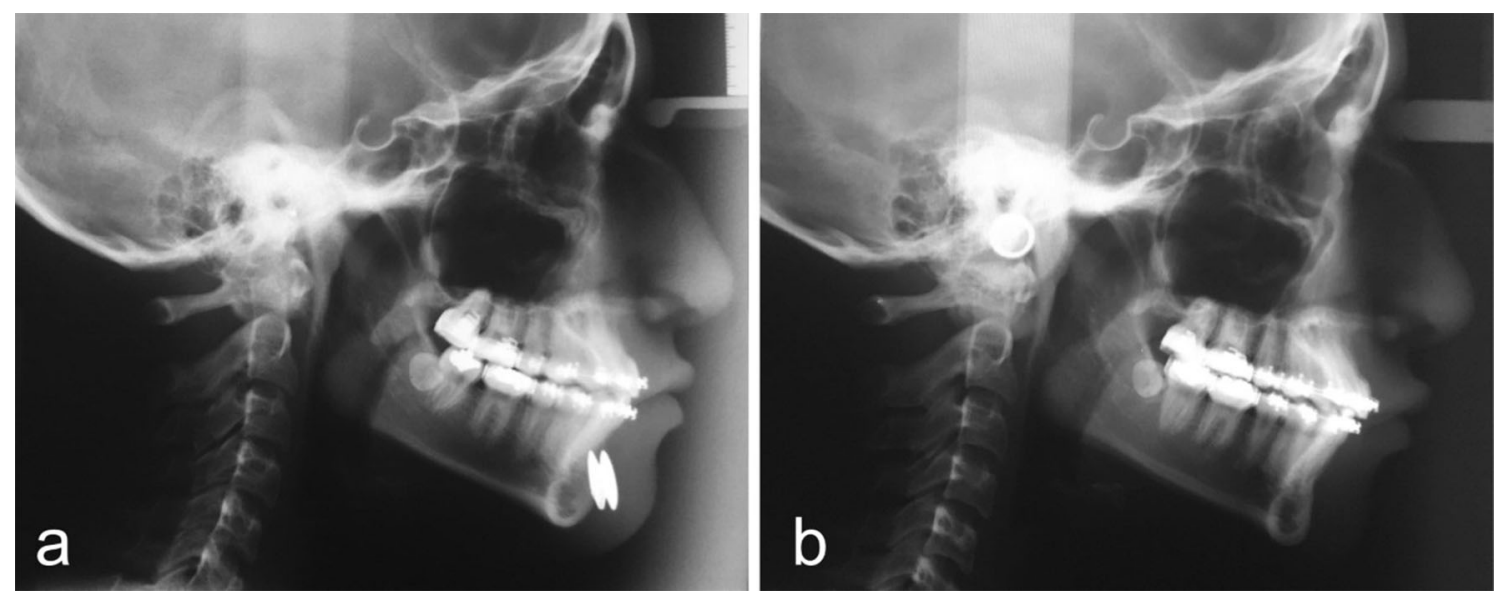

Fig 13 The cephalometric control (a-at the beginning and $\mathbf{b}$ - six months after the Modulator removal) showed a 5.76mm overall length increase of her mandible. The change in contour is noticeable, not only in the body and angle of the mandible but also in the chin area.

insertion of the Modulator is similar to the technique for the insertion of an alloplastic chin implant. Preliminary clinical results suggest that Modulation is indicated for patients with mandibular hypoplasia and microgenia with normal occlusion. Modulation can be an alternative to tissue fillers, alloplastic implants, mandibular osteotomies, BSSO, genioplasty, and distraction osteogenesis in selected clinical cases. BSSO, osteotomies, genioplasty, and distraction osteogenesis require general anesthesia, have a long postoperative recovery and they have their risk of postoperative complications. On the other hand, Modulation requires local anesthesia with sedation, have a fast recovery period, and a low risk of postoperative complications. Alloplastic implants are useful for aesthetic improvement of the facial profile, require local anesthesia with sedation, and have a fast recovery period. However, alloplastic implants are permanent implants and eventually may cause underlying bone resorption and foreign body reaction $[8,9]$. On the other hand, Modulation utilizes a Modulator, which is a temporary implant that is removed once a satisfactory change of facial profile is achieved. Continued investigations will include the 3D analysis (Vectra Technology, Canfield Scientific, Parsippany, NJ) of soft tissue response to placement as well as removal of the Modulator on the overall facial aesthetics [28, 54-56]. Resorbable tissue fillers offer an office-based, temporary solution for aesthetic improvement of the facial profile while Modulation offers a long-term correction of mandibular hypoplasia and microgenia. Other, emerging options for bone regeneration or generation include Theradaptive implants. This technology which is investigated for bone regeneration at this time is based application on application of bone morphogenic protein variant (called AMP-2) to guide migrating stem cells into bioactive implants acting as scaffolds to ensure formation of the bone where needed (within boundaries of the implants).
However, this technology effective for repair of bone gaps was not tested for bone "additive objective" such as augmentation of otherwise intact, healthy bone [55].

For programmable osteogenesis research, mostly focused on osteoinductive proteins and their delivery systems for repairs on bone defects, confining osteoinductive activity within boundaries of the delivery vehicle is one of the concerns [26, 27, 56]. One of the observed advantages of Modulator include protected or controlled bone generation, limited to the size of the implant. No uncontrolled prolapse of callus or newly formed bone into the platinumcoated device or soft tissue neighboring the implant was seen [57]. Excessive callus - which could be detrimental in aesthetic applications-formation was reported in some circumstances when external electrical stimulation was applied to enhance endochondral bone fractures healing. Protected bone generation just like protected bone regeneration is essential for bony contouring or defects repair in craniofacial surgery either cosmetic or reconstructive, respectively, [57]. Platinum's biocompatibility makes it ideal for coating for both short- and long-term medical implants, its high integrity causes that platinum surfaces can withstand stress without deformation or cracking [58]. Mechanisms how bone tissue behavior such as possibly cell migration, proliferation, differentiation and apoptosis all leading to controlled osteogenesis in response to electric stimulations and/or to mechanical-non-electrical field generating-implants strains certainly deserve future laboratory and clinical investigations [59,60].

One disadvantage of Modulation could be the current low availability of the Modulator. Notwithstanding, eventually the Modulator can be mass-produced which will lower the cost similarly to the trajectory of the development other high-tech medical devices. The current limitations of Modulation are that this technique may not be suitable for patients with severe craniofacial deformities. 


\section{Conclusion}

Preliminary clinical results suggest that Modulation can be a practical tool to augment bone contours indicated for patients with mandibular hypoplasia and microgenia with normal occlusion. We achieved acceptable long-term correction of mandibular hypoplasia and microgenia without using osteotomies, genioplasty, BSSO, distraction osteogenesis, alloplastic implants, or tissue fillers. Preliminary clinical results suggest that Modulation is a safe, minimally invasive, and effective alternative treatment for the longterm correction of mandibular hypoplasia and microgenia in selected cases. Further applications of Modulation in plastic surgery are currently being tested.

\section{Declarations}

Conflict of interest The authors declare that they have no conflict of interest to disclose.

Animal Experiments All applicable institutional and national guidelines for the care and use of animals were followed.

Ethical Approval All procedures performed in this study were in accordance with the ethical standards of the Investigational Review Board of Jalisco Institute for Reconstructive Plastic Surgery and national research committee and with the 1964 Helsinki Declaration and its later amendments or comparable ethical standards.

Informed Consent Informed consent was obtained from all patients before being enrolled in the study.

Open Access This article is licensed under a Creative Commons Attribution 4.0 International License, which permits use, sharing, adaptation, distribution and reproduction in any medium or format, as long as you give appropriate credit to the original author(s) and the source, provide a link to the Creative Commons licence, and indicate if changes were made. The images or other third party material in this article are included in the article's Creative Commons licence, unless indicated otherwise in a credit line to the material. If material is not included in the article's Creative Commons licence and your intended use is not permitted by statutory regulation or exceeds the permitted use, you will need to obtain permission directly from the copyright holder. To view a copy of this licence, visit http://creativecommons. org/licenses/by/4.0/.

\section{References}

1. Karp NS, Thome CH, McCarthy JG, Sissons HA (1990) Bone lengthening in the craniofacial skeleton. Ann Plast Surg 24(3):231-237

2. McCarthy JG, Schreiber J, Karp N, Thorne CH, Grayson BH (1992) Lengthening the human mandible by gradual distraction. Plast Reconstr Surg 89(1):1-8

3. Molina F, Ortiz Monasterio F (1995) Mandibular elongation and remodeling by distraction: a farewell to major osteotomies. Plast Reconstr Surg 96(4):825-840

4. McCarthy JG, Staffenberg DA, Wood RJ, Cutting CB, Grayson $\mathrm{BH}$, Thorne $\mathrm{CH}$ (1995) Introduction of an intraoral bonelengthening device. Plast Reconstr Surg 96(4):978-981
5. Huang CS, Ko WC, Lin WY, Liou EJ, Hong KF, Chen YR (1999) Mandibular lengthening by distraction osteogenesis in children: a one-year follow-up study. Cleft Palate Craniofac J 36(3):269-274

6. Li KK, Powel NB, Riley RW, Guilleminault C (2002) Distraction osteogenesis in adult obstructive sleep apnea surgery: a preliminary report. J Oral Maxillofac Surg 60(1):6-10

7. Steinbacher DM, Kaban LB, Troulis MJ (2005) Mandibular advancement by distraction osteogenesis for tracheostomy-dependent children with severe micrognathia. J Oral Maxillofac Surg 63(8):1072-1079

8. Friedland JA, Coccaro PJ, Converse JM (1976) Retrospective cephalometric analysis of mandibular bone absorption under silicone rubber chin implants. Plast Reconstr Surg 57(2):144-151

9. Choen SR, Mardach OL, Kawamoto HK (1991) Chin disfigurement following removal of alloplastic chin implants. Plast Reconstr Surg 88(1):62-66

10. Fukada E, Yasuda I (1957) On the piezoelectric effect of bone. J Phys Soc Jpn 12:1158-1162

11. Bassett CA, Becker RO (1962) Generation of electric potentials by bone in response to mechanical stress. Science 137(3535): 1063-1064

12. Enlow DH (1963) Principles of bone remodeling. Springfield, Illinois, Charles C Thomas Company

13. Reinish GB, Norwick AS (1975) Piezoelectric properties of bone as functions of moisture content. Nature 253:626-627

14. Fukada E, Ueda H, Rinaldi R (1976) Piezoelectric and related properties of hydrated collagen. Biophys J 16(8):911-918

15. Brighton CT, Friedenberg ZB, Black J, Esterhai JL, Mitchell JE, Montique F (1981) Electrically induced osteogenesis: relationship between charge, current density, and the amount of bone formed: introduction of a new cathode concept. Clin Orthop Relat Res 161:122-132

16. Fukada E (1982) Electrical phenomena in biorheology. Biorheology 19(1/2):15-27

17. Bassett CA, Valdes MG, Hernandez E (1982) Modification of fracture repair with selected pulsing electromagnetic fields. J Bone Joint Surg Am 64(6):888-895

18. Smith RL, Nagel DA (1983) Effects of pulsing electromagnetic fields on bone growth and articular cartilage. Clin Orthop Relat Res 181:277-282

19. Gerling JA, Sinclair PM, Roa RL (1985) The effect of pulsating electromagnetic fields on condylar growth in guinea pigs. Am J Orthod 87(3):211-223

20. McLeod KJ, Rubin CT (1992) The effect of low-frequency electrical fields on osteogenesis. J Bone Joint Surg Am 74(6):920-929

21. Takano-Yamamoto T, Kawakami M, Sakuda M (1992) Effect of a pulsing electromagnetic field on demineralized bone-matrixinduced bone formation in a bony defect in the premaxilla of rats. J Dent Res 71(12):1920-1925

22. Rubin CT, Donahue HJ, Rubin JE, McLeod KJ (1993) Optimization of electric fields parameters for the control of bone remodeling: exploitation of an indigenous mechanism for the prevention of osteopenia. J Bone Miner Res 2:S573-581

23. Yonemori K, Matsunaga S, Ishidou Y, Maeda S, Yoshida $\mathrm{H}$ (1996) Early effects of electrical stimulation on osteogenesis. Bone 19:173-180

24. Matsugana S, Sakou T, Ijiri K (1996) Osteogenesis by pulsing electromagnetic fields (PEMFs): optimum stimulation setting. In Vivo 10(3):351-356

25. Karras SC, Wolford LM (1998) Augmentation genioplasty with hard tissue replacement implants. J Oral Maxillofac Surg 56(5):549-552

26. Brekke JH, Toth JM (1998) Principles of tissue engineering applied to programmable osteogenesis. J Biomed Mater Res (Appl Biomater) 43(4):380-398 
27. Plenk H (1998) Prosthesis-bone interface. J Biomed Mater Res (Appl Biomater) 43(4):350-355

28. Spadaro JA (1997) Mechanical and electrical interactions in bone remodeling. Bioelectromagnetics 18(3):193-202

29. Lohmann CH, Schwartz Z, Liu Y, Guerkov H, Dean DD, Simon B, Boyan BD (2000) Pulsed electromagnetic field stimulation of MG63 osteoblast-like cells affects differentiation and local factor production. J Orthop Res 18(4):637-646

30. Diniz P, Shomura K, Soejima K, Ito G (2002) Effects of pulsed electromagnetic field (PEMF) stimulation on bone tissue like formation are dependent on the maturation stages of the osteoblasts. Bioelectromagnetics 23(5):398-405

31. Chang WH, Chen LT, Sun JS, Lin FH (2004) Effect of pulseburst electromagnetic field stimulation on osteoblast cell activities. Bioelectromagnetics 25(6):457-465

32. Qu C, Qin QH, Kang Y (2006) A hypothetical mechanism of bone remodeling and modeling under electromagnetic loads. Biomaterials 27(21):4050-4057

33. Wei Y, Xiaolin H, Tao S (2008) Effects of extremely low-frequency-pulsed electromagnetic field on different-derived osteoblast-like cells. Electromagn Biol Med 27(3):298-311

34. Jansen JH, van der Jagt OP, Punt BJ, Verhaar JA, van Leeuwen JP, Weinans H, Jahr H (2010) Stimulation of osteogenic differentiation in human osteoprogenitor cells by pulsed electromagnetic fields: an in vitro study. BMC Musculoskelet Disord 11:188

35. Zhou J, Ming LG, Ge BF, Wang JQ, Zhu RQ, Wei Z, Ma HP, Xian CJ, Chen KM (2011) Effects of $50 \mathrm{~Hz}$ sinusoidal electromagnetic fields of different intensities on proliferation, differentiation and mineralization potentials of rat osteoblasts. Bone 49(4):753-761

36. Liu C, Yu J, Yang Y, Tang X, Zhao D, Zhao W, Wu H (2013) Effect of $1 \mathrm{mT}$ sinusoidal electromagnetic fields on proliferation and osteogenic differentiation of rat bone marrow mesenchymal stromal cells. Bioelectromagnetics 34(6):453-464

37. Barnaba S, Papalia R, Ruzzini L, Sgambato A, Maffulli N, Denaro V (2013) Effect of pulsed electromagnetic fields on human osteoblast cultures. Physiother Res Int 18(2):109-114

38. Hong JM, Kang KS, Yi HG, Kim SY, Cho DW (2014) Electromagnetically controllable osteoclast activity. Bone 62:99-107

39. Wang J, An Y, Li F, Li D, Jing D, Guo T, Luo E, Ma C (2014) The effects of pulsed electromagnetic field on the functions of osteoblasts on implant surfaces with different topographies. Acta Biomater 10(2):975-985

40. Ross CL, Siriwardane M, Almeida-Porada G, Porada CD, Brink P, Christ GJ, Harrison BS (2015) The effect of low-frequency electromagnetic field on human bone marrow stem/progenitor cell differentiation. Stem Cell Res 15(1):96-108

41. Ehnert S, Falldorf K, Fentz AK, Ziegler P, Schröter S, Freude T, Ochs BG, Stacke C, Ronniger M, Sachtleben J, Nussler AK (2015) Primary human osteoblasts with reduced alkaline phosphatase and matrix mineralization baseline capacity are responsive to extremely low frequency pulsed electromagnetic field exposure-clinical implication possible. Bone Rep 18(3):48-56

42. Rajabi AH, Jaffe M, Arinzeh TL (2015) Piezoelectric materials for tissue regeneration: A review. Acta Biomater 24(September): 12-23

43. Jacob J, More N, Kalia K, Kapusetti G (2018) Piezoelectric smart biomaterials for bone and cartilage tissue engineering. Inflamm Regen 38(2):1-11

44. Oltean-Dan D, Dogaru GB, Apostu D, Mester A, Benea HRC, Paiusan MG, Popa CO, Jianu EM, Bodizs GI, Berce C, Toader AM, Tomoaia G (2019) Enhancement of bone consolidation using high-frequency pulsed electromagnetic fields (HF-PEMFs):
An experimental study on rats. Bosn $\mathrm{J}$ Basic Med Sci 19(2):201-209

45. Ehnert S, Schröter S, Aspera-Werz RH, Eisler W, Falldorf K, Ronniger M, Nussler AK (2019) Translational Insights into extremely low frequency pulsed electromagnetic fields (ELFPEMFs) for Bone regeneration after trauma and orthopedic surgery. J Clin Med 8(12):2028-2050

46. Galli C, Pedrazzi G, Guizzardi S (2019) The cellular effects of pulsed electromagnetic fields on osteoblasts: a review. Bioelectromagnetics 40(4):211-233

47. Galli C, Colangelo M, Pedrazzi G, Guizzardi S (2019) the response of osteoblasts and bone to sinusoidal electromagnetic fields: insights from the literature. Calcif Tissue Int 105(2):127-147

48. Zhou J, Gao YH, Zhu BY, Shao JL, Ma HP, Xian CJ, Chen KM (2019) Sinusoidal electromagnetic fields increase peak bone mass in rats by activating $\mathrm{Wnt} 10 \mathrm{~b} / \beta$-catenin in primary cilia of osteoblasts. J Bone Miner Res 34(7):1336-1351

49. Khare D, Basu B, Dubey AK (2020) Electrical stimulation and piezoelectric biomaterials for bone tissue engineering applications. Biomaterials 258:120280

50. Kim C, Yang HJ, Cho TH, Lee BS, Gwon TM, Shin S, Kim IS, Kim SJ, Hwang SJ (2020) Implantable electrical stimulation bioreactor with liquid crystal polymer-based electrodes for enhanced bone regeneration at mandibular large defects in rabbit. Med Biol Eng Comput 58(2):383-399

51. Leppik L, Oliveira KMC, Bhavsar MB, Barker JH (2020) Electrical stimulation in bone tissue engineering treatments. Eur $\mathrm{J}$ Trauma Emerg Surg 46(2):231-244

52. Zhang B, Xie Y, Ni Z, Chen L (2020) Effects and mechanisms of exogenous electromagnetic field on bone cells: a review. Bioelectromagnetics 41(4):263-278

53. Griffin M, Bayat A (2011) Electrical stimulation in bone healing: critical analysis by evaluating levels of evidence. Eplasty 11:303-353

54. Ewing M, Ross RB (1992) Soft tissue response to mandibular advancement and genioplasty. Am J Orthod Dentofacial Orthop 101:550-551

55. Dutton G (2021) To mend difficult breaks, try porous implants treated with "Bone Paint." Genetic Eng and Biotech News 41:20-21

56. Cohen S, Holmes R, Amis P, Fichtner H (2000) Internal craniofacial distraction with biodegradable devices: early stabilization and protected bone regeneration. J Craniofac Surg 11:354-366

57. Sutro CJ, Sutro WH (1983) The relationship of paraarticular ossification and excess callus formation in fracture healing to local electric and magnetic fields. Bull Hosp Jt Dis Orthop Inst 43:15-27

58. Geninatti T, Bruno G, Barile B, Hood RL, Farina M, Schmulen J, Canavese G, Grattoni A (2015) Impendance characterization, degradation, and in vitro biocompatibility for platinum electrodes on BioMEMS. Biomed Microdevices 17(1):24-47

59. Shuai C, Yang W, Peng S, Gao C, Guo W, Lai Y, Feng P (2018) Physical stimulus and their osteogenesis-inducing mechanisms. Bioprint 4:1-20

60. Simmons CA, Meguid SA, Pilliar RM (2001) Mechanical regulation of localized and appositional bone formation around boneinterfacing implants. J Biomed Mater Res 55:63-71

Publisher's Note Springer Nature remains neutral with regard to jurisdictional claims in published maps and institutional affiliations. 